\title{
Notas sobre a análise antropológica de setores do Estado brasileiro
}

\author{
Ciméa Bevilaqua \\ Professora do Departamento de Antropologia - UFPR e NAU/USP \\ Piero de Camargo Leirner \\ Professor do Departamento de Ciências Sociais - UFSCAR e NAU/ \\ USP
}

\begin{abstract}
RESUMO: Este artigo pretende discutir algumas questões que envolvem a análise antropológica do Estado, tomando como base duas experiências etnográficas distintas: uma pesquisa com o exército, outra com órgãos de defesa do consumidor. Com esse objetivo, desenvolve-se uma reflexão preliminar sobre problemas teóricos e metodológicos relacionados ao estudo de objetos dessa natureza em nossa sociedade.
\end{abstract}

PALAVRAS-CHAVE: Estado, Antropologia Urbana, Etnografia

O interesse da antropologia brasileira pelo estudo etnográfico de setores que compreendem o universo do Estado é recente ${ }^{1}$. Nos últimos anos, porém, o surgimento de trabalhos ainda esparsos, de pesquisadores geralmente jovens e em fase de formação, começa a delinear uma tendência crescente de realização de pesquisas com setores da burocracia estatal ${ }^{2}$. A perspectiva etnográfica que os caracteriza, assim como suas preocupações teóricas, conferem a esses novos estudos antropológicos - ou, pelo menos, a boa parte deles - um caráter marcadamente diferenciado em relação às abordagens mais características da sociologia e da ciência política nas suas análises do Estado brasileiro.

Embora distantes no tempo e no espaço dos clássicos da "antropologia política” da década de 1940, esses trabalhos respiram algo de sua inspiração. 
Como é sabido, uma das principais contribuições dos primeiros estudos antropológicos de sistemas políticos, a partir do material africano, foi retirar a questão do "político" da esfera tradicionalmente atribuída a ele pela filosofia e pela ciência política: o Estado. Desse modo, inaugurava-se a possibilidade de abordar a política não somente a partir da construção instrumental de aparatos de poder, mas como algo disseminado no socius através de processos de identificação e segmentação. Inversamente, as instituições políticas podiam deixar de ser pensadas exclusivamente em termos de poder. Já nas décadas de 1960 e 1970, contribuições de maior fôlego teórico surgidas da vertente francesa da disciplina - em especial os trabalhos de Clastres (1978) e outros ${ }^{3}$ - tornaram possível falar de uma política transversal ao Estado, enraizada em planos mais profundos da sociabilidade humana.

É a incorporação dessa tradição de pesquisa que permite aos antropólogos retomar a questão do Estado como objeto de suas preocupações, especialmente quando se voltam mais intensamente ao estudo das sociedades de que fazem parte, mas sem que isso signifique uma reaproximação com as abordagens consagradas no âmbito de outras disciplinas. Ao contrário, as reflexões desenvolvidas no próprio campo da antropologia não somente demonstram o equívoco de se imaginar o "político" restrito à esfera do Estado, como também levam a pensar, curiosamente, em dimensões "anti-estatais" do próprio Estado. Trata-se de reconhecer, enfim, que aqueles princípios mais gerais e mais abstratos que fundamentam as relações sociais - de que falam, por exemplo, Mauss e Lévi-Strauss - são também inerentes à organização interna das instituições estatais e a suas relações com outros setores da sociedade.

$\mathrm{Na}$ falta de designação mais apropriada, os estudos que se preocupam em explorar etnograficamente o universo do Estado acabam sendo acomodados precariamente sob o rótulo de "antropologia urbana", como se este pudesse conter tudo aquilo que escapa ao campo tradicional da 
"etnologia". Mas isto não se faz sem prejuízos, já que a distinção canônica em dois campos disciplinares - a etnologia e a antropologia urbana está longe de possuir um caráter meramente descritivo. Ainda que haja certo consenso, atualmente, sobre a inexistência de impedimentos a priori para a realização de estudos antropológicos em contextos mais ou menos próximos da experiência do pesquisador ${ }^{4}$, a própria construção dos campos disciplinares a partir desses "divisores"5 acaba, de modo geral, tornando problemática uma melhor definição do que seria uma "antropologia do Estado".

Não por acaso, mesmo quando se admite que a chamada "antropologia urbana" possa apresentar uma contribuição original, espera-se que ela decorra do estudo de grupos e processos "marginais" e "minoritários". À antropologia que trata das instituições, agentes e processos hegemônicos da nossa sociedade, caberia uma maior interlocução com a sociologia e a ciência política, sendo reduzida não raro à desconfortável condição de apêndice ilustrativo das grandes contribuições macro-sociológicas.

O objetivo deste texto é argumentar que divisores como "distante" e "perto", "marginal" e "central" são pouco operativos, em si mesmos e, especialmente, para a construção de uma antropologia de setores estatais. Não somente certas formulações clássicas possuem um grande rendimento para esses estudos, como possibilitam uma interpretação original - e não residual - , em relação às das chamadas ciências irmãs, dos fenômenos sociais que envolvem o Estado.

O ponto de partida da reflexão é o exame de algumas vertentes do debate metodológico sobre a antropologia "urbana" e suas implicações. Em seguida procuraremos indicar, com dois exemplos etnográficos, a possibilidade de abordar contextos empíricos bastante diversos, na esfera da organização estatal, a partir de uma perspectiva comum. Com base nesse exercício retomaremos, finalmente, a discussão inicial, procurando apontar perspectivas para uma investigação de diferentes setores do Estado inspirada numa tradição teórica desenvolvida em outros contextos. 


\section{Antropologia urbana e antropologia de setores do Estado6}

Não é novidade que a chamada antropologia urbana se dedicou prioritariamente a pesquisar grupos tomados como estando "à margem" dos grandes processos hegemônicos (entendidos como aqueles que agem diretamente sobre o núcleo de poder) da nossa sociedade ${ }^{7}$. Como uma espécie de reação a essa tendência, que se traduzia também em certa marginalidade da própria antropologia em relação às demais ciências sociais, começa a tomar forma entre os antropólogos brasileiros, a partir dos anos 70, um longo debate sobre a validade da transposição de marcos teórico-metodológicos das sociedades de tradição não ocidental para as modernas sociedades industriais. Questionava-se, de um lado, a validade de categorias tradicionais da antropologia para o entendimento de sociedades modernas e, de outro, as possibilidades de transpor categorias de cunho mais sociológico para a reflexão antropológica ${ }^{8}$.

Talvez como resultado do próprio vigor desse debate, os estudos urbanos trouxeram uma inegável contribuição nos anos 70 e 80, redimensionando conceitos clássicos da sociologia para a compreensão de processos sociais que, até aquele momento, eram tidos como meros subprodutos dos processos hegemônicos ${ }^{9}$. Passado esse impulso inicial, porém, boa parte da antropologia urbana se contentou com a adição de novos termos à série empírica, assumindo implicitamente que seu escopo se limitava a fenômenos e grupos sociais "minoritários", como se somente estes pudessem oferecer um léxico original para a disciplina.

O legado duradouro dessa opção conjuntural foi a tendência, amplamente difundida entre os demais cientistas sociais, de reduzir a antropologia urbana ao estudo de pequenos grupos étnicos e religiosos, movimentos sociais estritamente localizados ou práticas mais ou menos marginais ${ }^{10}$. Um exemplo emblemático é a famosa acusação - de um cientista político - de que a disciplina se limitaria à transcrição de "longos depoimentos de mulheres pobres da periferia urbana" 11 . Mas é preciso admitir que essa 
Revista de Antropologia, São Paulo, USP, 2000, v. 43 nº 2.

visão empobrecedora é muitas vezes compartilhada pelos próprios antropólogos, quando imaginam poder reencontrar ou recriar num contexto urbano e industrial os universos sociais de pequena escala que foram tradicionalmente o objeto da disciplina. A "tentação da aldeia"12 traz consigo também outra, ainda mais grave, de natureza epistemológica: a suposição de que a antropologia (ou qualquer ciência) se define por um objeto empírico, ou que suas preocupações teóricas decorrem imediatamente do objeto empírico.

Quando cedem a essa dupla tentação, os antropólogos "urbanos" efetivamente se tornam incapazes de contribuir para a compreensão de processos sociais mais amplos - ou, o que é a mesma coisa, refletir sobre a articulação entre o contexto local e processos que o ultrapassam - e de formular contribuições teóricas mais consistentes. E, assim, acabam mesmo merecedores da crítica que lhes é dirigida por outros cientistas sociais e mesmo por alguns colegas antropólogos que, no fundo, compartilham da mesma visão - apenas estão situados do outro lado do "grande divisor". Ao procurar reproduzir diretamente, no mundo urbano e industrial, uma tradição construída no estudo de sociedades de pequena escala, esta vertente da antropologia urbana acaba fazendo o contrário do que deseja: involuntariamente, trai a tradição à qual pretende se manter fiel, cujo propósito maior sempre foi o de, partindo do dado nativo, chegar a modelos que possam transcender as especificidades do contexto local.

Evidentemente, não há como negar que a abordagem antropológica de grupos e processos mais ou menos "marginais" de nossa sociedade trouxe e continua trazendo contribuições interessantes. Mas o faz, principalmente, quando mostra que seu isolamento ou marginalidade não existe, e que mesmo fenômenos aparentemente muito localizados se articulam a outras dimensões da vida social e a processos bem mais complexos.

A antropologia jamais pretendeu se limitar ao estudo do "marginal" (cuja definição, aliás, é sempre problemática). As maiores contribuições da disciplina vieram, ao contrário, do estudo dos fenômenos mais centrais de diferentes sociedades. A definição do que é central é que varia conforme 
o contexto, e a longa tradição antropológica no estudo do parentesco, da religião, dos mitos e dos próprios sistemas políticos não deixa dúvidas disso.

Assim, não há razão para se descartar uma antropologia do Estado, das elites ou da burocracia ${ }^{13}$, quando tratamos da nossa sociedade. Ao contrário, as experiências recentes indicam que esse novo campo de estudos pode trazer contribuições substantivas não somente para a compreensão dos contextos específicos de cada pesquisa, mas para o conjunto da disciplina. Sob esse aspecto, algumas aproximações com modelos elaborados a partir de sociedades de tradição não ocidental são particularmente frutíferas, na medida em que revelam princípios muito gerais da sociabilidade humana. A resposta para os dilemas da antropologia "urbana" enunciados acima pode não estar na transposição de conceitos de outras ciências sociais, mas na recuperação criativa de nossa própria tradição conceptual.

Alguns dos maiores clássicos da literatura antropológica foram dedicados às diferentes formas de organização do Estado e/ou aos processos e agentes políticos ${ }^{14}$. Por diferentes razões, algumas delas examinadas acima, os antropólogos deixaram o tema de lado no que diz respeito à nossa própria sociedade, assumindo indiretamente que este seria o campo de outros cientistas sociais ${ }^{15}$. Ora, uma das primeiras lições da antropologia é justamente buscar aquilo que, do ponto de vista nativo, é o mais relevante e significativo. Sob esse aspecto, não se pode desconhecer que, no Brasil, as relações com diferentes vertentes do Estado constituem uma parte importante da vida cotidiana, das esperanças e das preocupações.

Em resumo, enquanto certa vertente da antropologia "urbana" se preocupa em estabelecer artificialmente uma continuidade empírica entre a etnologia e os estudos urbanos, mantendo-se ao mesmo tempo distante do patrimônio teórico da antropologia clássica, assumimos que o mais interessante seja construir, no campo dos estudos "urbanos", uma continuidade produtiva com as formulações teóricas mais fundamentais da disciplina, desenvolvidas a partir de seus contextos tradicionais de pesquisa ${ }^{16}$. Com isso, não se está sugerindo que os antropólogos devam competir ou pretender ocupar o lugar de cientistas políticos, sociólogos, economistas e juristas. A visão 
Revista de Antropologia, São Paulo, USP, 2000, v. 43 nº 2.

antropológica não se opõe, mas talvez seja capaz de englobar a visão desses últimos, como um olhar mais distanciado engloba outro menos distanciado, sem excluí-lo ${ }^{17}$.

$$
* \quad * \quad *
$$

Propomos aqui uma reflexão preliminar, a partir de duas pesquisas que estamos desenvolvendo de modo independente, com diferentes setores da burocracia estatal. É verdade que a quase totalidade dos estudos sobre esse tema - ou seja, o campo acadêmico de debate - a princípio se desenvolveu em outras ciências sociais. Está concentrada, sobretudo, numa apropriação da discussão weberiana de burocracia, cujo tipo ideal de organização burocrática já foi usado para pensar os fundamentos do Estado moderno (Weber, 1994; Bendix, 1996). Entre as suas derivações vemos, por exemplo, trabalhos que mostram como a organização da burocracia, no interior do Estado brasileiro, remete a um problema mais amplo da disposição das esferas pública e privada, desde os tempos coloniais ${ }^{18}$.

É verdade também que esses e outros tantos estudos que discutem a chamada relação entre Estado e classes da sociedade civil - a partir de temas como populismo, autoritarismo ou corporativismo ${ }^{19}$ - acabam por se inserir num horizonte de discussões que situa os grupos burocráticos ora como decorrência, ora como fatores (e a ordem dos fatores, neste caso, não afeta o produto) de processos estruturais mais amplos desenvolvimento, setores produtivos, classes sociais, construção de espaços públicos, por exemplo -, sempre com um olhar filtrado pelos códigos das próprias sociedades industriais.

Em outras palavras, não existe a preocupação (que é especificamente antropológica) em procurar nas nossas burocracias nem modelos mais abstratos de organização social, nem objetos que falam de relações mais amplas que as do contexto sócio-histórico do Estado brasileiro. Neste sentido, comparar o exército ou o judiciário, por exemplo, com a organização segmentária Nuer ou com o sistema de trocas trobriandês só poderia 
consistir numa aberração: no caso das ciências “irmãs”, o contexto ou o horizonte que fornece os códigos prevalece sobre o objeto.

Na perspectiva de um olhar distanciado, porém, não há razão a priori para descartar aproximações como essas que, realizadas com critério, podem oferecer contribuições consistentes ${ }^{20}$. Assim, acreditamos que as pesquisas que estamos desenvolvendo - e que, à primeira vista, têm pouco ou nada em comum - podem contribuir para uma mesma reflexão teórica e metodológica.

Um dos trabalhos diz respeito ao exército, em especial às maneiras como os militares constituem um grupo com uma identidade muito bem formatada a partir de uma codificação hierárquica do mundo e de suas relações. O outro está voltado à questão dos direitos do consumidor, particularmente às condições concretas em que tais direitos são reivindicados e implementados (ou não) com a mediação de órgãos estatais. De um lado, uma corporação fechada, que zela pelo bem comum; de outro, instituições de atendimento ao público (abertas, portanto), mas que se destinam a resolver questões individuais. De um lado o exército, em tese voltado para a "guerra externa"; de outro, instituições que, por sua vez, entram em ação quando irrompe a "guerra interna", nas relações de mercado. Ou, numa linguagem menos metafórica, a primeira parte do princípio de que o enfrentamento é um recurso legítimo para restabelecer a paz, enquanto a outra recorre a meios pacíficos justamente para evitar a efetivação do conflito num contexto, de saída, assimétrico.

Colocando em perspectiva essas duas vertentes da organização estatal, nossa proposta é mostrar que elas são também modelos de organização social e, desse modo, podem se constituir em objetos comparáveis, menos pelo fundo contextual e histórico a que se referem, e mais pela forma particular pela qual realizam operações universais, a saber: a organização das relações de troca e reciprocidade no interior de grupos e/ou deles para fora. 
Revista de Antropologia, São Paulo, USP, 2000, v. 43 nº 2.

\section{Exército}

O exércitoé uma instituição nacional e permanente, um poder público, que possui em seu efetivo aproximadamente 180 mil indivíduos sob uma rígida cadeia disciplinar, além de um corpo de reservistas. Porém, entre estes indivíduos há uma parcela em cuja auto-imagem há a visão de que apenas eles são militares "de fato": os militares de carreira, que representam hoje aproximadamente metade do efetivo acima ${ }^{21}$, excluindo desta parcela tanto aqueles que se encontram na condição transitória do recrutamento imposto pelo serviço militar obrigatório quanto os que pertencem ao corpo da reserva $^{22}$. Portanto, nessa construção, o militar "legítimo" - que inclusive usufrui desta condição - é aquele consagrado por uma carreira que tem como trajetória única o pertencimento a uma cadeia de comandoobediência pela qual cada indivíduo tem o direito de realizar uma escalada hierárquica ${ }^{23}$. Basicamente, este foi o conjunto de pessoas - os militares de carreira - a cujo campo de pesquisa se teve acesso. Mas, esta trajetória, apesar de ocorrer sob o aval de duas instituições públicas - exército e universidade -, não ocorreu sem percalços.

A partir de uma dificuldade surgida em campo em meados de 1993, começou-se a questionar o sentido não somente da configuração da relação pesquisador-pesquisado mas, também, como isto estava ligado aos lugares que havia acesso e aos lugares que não havia acesso para pesquisar $^{24}$. Juntamente, percebeu-se que não somente os locais, mas havia pessoas com atribuições específicas a quem tinha acesso, enquanto a outras isto me era restrito ${ }^{25}$. E mais, percebeu-se a partir de uma mudança de postos das pessoas com quem tinha contato que a relação pesquisador-pesquisado não era com estas pessoas, mas, sim, com estes postos, por meio dos quais qualquer pessoa que os ocupasse teria a atribuição de estabelecer um contato com a parcela do mundo civil que pertence à Universidade. Finalmente, percebeu-se com isto que locais, pessoas e atribuições eram fatos relacionados, e, ainda, que também o mundo de fora, através das posições que o pesquisador ocupou para a 
instituição, também era definido de acordo com o mesmo critério classificatório que liga pessoas, locais e atribuições.

Neste quadro, esses militares acabam realizando a construção de uma espécie de grade classificatória em que a categoria militar aparece de forma restritiva e hierarquizada, dependendo da situação em que ela é exigida: entre os próprios oficiais de carreira, há aqueles que se definem por estar numa Arma (infantaria, cavalaria, intendência, etc.) mais militar em oposição a uma menos militar ou mais técnica (Castro, 1990: 102); ainda entre oficiais, entre aqueles que se situam melhor na escala hierárquica e aqueles pior situados ${ }^{26}$, tendo os primeiros mais vocação militar que os últimos; entre oficiais e praças, os primeiros se consideram mais militares que os últimos, especialmente os últimos da cadeia de comando, os recrutas (Costa, 1985); entre as três forças, um oficial do exército se considera mais militar que um da Aeronáutica, por exemplo; entre os chamados militares da ativa e os reservistas; e, finalmente, entre os que se consideram como militares, se reconhecendo como um grupo distinto do resto da sociedade, e os paisanos - como bem apontou Castro (1990).

Durante a pesquisa, ocorreram situações que demonstraram simultaneamente esta clivagem interna e uma generalização do mundo exterior (muito próximas em termos estruturais ao modelo segmentar nue ${ }^{27}$ ). Além disso, observou-se características peculiares à organização militar que remetiam à idéia de que a cadeia de comando se constitui ao mesmo tempo em um bloco único, pelas características intrínsecas da disciplina militar, mas também, interiormente, segmentada em múltiplos planos que conferem significados diversos perante situações determinadas. Foi esta ambigüidade que permitiu ao mesmo tempo reconstituir um único "ponto de vista militar" e distinguir diferentes níveis de discursos e práticas dentro da corporação, mostrando que a maneira de classificar as coisas passa pelo princípio organizacional desses que se consideram "os militares".

A regra que fica da subtração entre esses cenários e esses atores remeteu ao universo da hierarquia, pois, já sabendo de antemão que havia uma organização burocrática - no sentido de uma burocracia típica tal como 
definida por $\mathrm{Weber}^{28}$ - que dividia tarefas no exército, somou-se o fato depois sabido que cada pessoa dentro da corporação possui uma classificação própria, e que isto criava sutilezas na importância a cada um atribuída na cadeia de comando-obediência. Desse modo, além de estratos, patentes, departamentos e segmentos, temos uma complexa malha classificatória que abrange a posição de cada um dentro da força ${ }^{29}$. Então, ao contrário do que se aponta em geral para os sistemas burocráticos (do qual o militar seria exemplar, segundo Weber), a hierarquia não se constitui no nosso caso numa simples "pirâmide" entre patentes em cadeia e numa seccionalização em departamentos especializados, mas, antes, constitui uma complexa rede de classificações que segue vários princípios de segmentação, abarcando desde o indivíduo singular até todo o conjunto "exército", e que, por isso, ela "totaliza" as dimensões da vida daqueles que nela estão inseridos - os que participam da carreira militar.

Desse modo, a hierarquia militar, ao mesmo tempo em que totaliza, sob a cadeia de comando e obediência, criando na visão interna uma série de clivagens em relação à sociedade envolvente, "endogamicamente" opera com os caracteres da coisa pública, constituindo assim a idéia de que as dimensões próprias da vida militar são as dimensões próprias da vida nacional.

Como resultado geral dessa disposição da organização burocrática está o fato que esta instituição pública opera, num registro sociológico mais amplo, sob o espectro de um grupo fechado, mas internamente se assume como a coisa pública por excelência, assumindo todos os principais caracteres desta-especialmente o individualismo competitivo-, enquanto que o resto da sociedade seria composta de grupos particulares fechados em seus interesses, o que de certa maneira "justificaria", segundo o ponto de vista nativo, todas as suas intervenções na história política. E, de fato, essa visão de mundo estaria espelhada na sociabilidade interna, uma vez que, "para dentro", os caracteres universais do individualismo e da livre concorrência estariam calcados num princípio ativo que moveria toda uma organicidade e cosmologia de uma organização que equaciona competição e solidariedade social. 
Portanto, a relação de pesquisa que se destacou, daí ter incorporado tantos dilemas: de um lado, tratar de uma instituição que, por ser pública, está relegada a uma lógica comum e sobre a qual inclusive deveríamos ter alguma ingerência; de outro, uma corporação que está longinquamente cerrada sob uma cosmologia distinta.

Tudo isso vem dos desdobramentos de uma pesquisa de campo que demonstrou que, na base desta cosmologia, está um princípio de organização social que faz um equacionamento sui generis da relação indivíduosociedade. De um lado, baseada no pressuposto de uma cadeia de comando que indica um fechamento endogâmico em relação à sociedade envolvente, enunciando um princípio de constituição de uma totalidade que se impõe sobre uma forte experiência socializadora entre seus agentes; de outro, ainda que sob a forma homogeneizadora da cadeia disciplinar, temos indivíduos em livre competição e com múltiplas possibilidades dentro da cadeia de relações pessoais para se traçar uma trajetória de ascensão dentro da força.

Desse modo, se de um lado temos papéis sociais prescritos e uma relação entre a instituição e seus agentes que pressupõe uma totalidade "holista", de outro, temos uma hierarquização tão exacerbada na organização interna que chegamos a uma espécie paradoxal de "castas de um homem só" ${ }^{30}$ (Leirner, 1997), com indivíduos hierarquicamente superpostos mas ao mesmo tempo dotados de múltiplas possibilidades de mobilidade dentro dessa fila.

Parece-nos que o que há de maior interesse neste tipo de enunciado que a hierarquia militar revela está no fato de ela conjugar elementos geralmente tomados pela literatura antropológica como relativamente discrepantes. Estes estariam situados na clássica oposição entre princípios individualistas e holistas que, na formulação dumontiana, assumiram o estatuto de oposições hierárquicas (Dumont, 1992). A hierarquia militar, embora logicamente seja uma hierarquia como qualquer outra, sociologicamente aponta para um tipo de solução organizacional diferenciada da tipologia de Dumont. 
Isto nos leva para um duplo desdobramento em relação às discussões que elencamos neste artigo. O primeiro, e mais claro, é a idéia de que a pesquisa etnográfica com o exército pôde oferecer um panorama sobre a constituição interna da instituição militar, constituição esta que a sociologia e a ciência política, quando não ignoraram sumariamente, apenas apontavam tangencialmente para algumas de suas características. Isto, obviamente, pode nos levar inclusive a traçar novos fundamentos para o comportamento da instituição militar na nossa história. O segundo está no plano comparativo com o material antropológico e sociológico disponível sobre sistemas hierárquicos, que, invariavelmente, operava na dicotomia de origem durkheimiana entre indivíduo e sociedade. Sem abandonar a proposição, temos a chance de ver como um novo material etnográfico, ainda que aparentemente tão próximo, oferece novas perspectivas para pensar certos arranjos sociológicos já clássicos, seja a hierarquia “castas”, seja a cadeia disciplinar de "tipo burocrático". Assim, ao mesmo tempo em que oferece uma nova perspectiva em relação aos estudos macro-sociológicos, a antropologia deste tipo de setor do Estado pode discutir e trabalhar categorias canônicas da própria antropologia.

Desse modo, pensando nesta instituição que tantas vezes atuou no cenário mais amplo de nossa sociedade, somos levados a tecer, a partir de velhos procedimentos metodológicos, novas considerações a respeito das possibilidades de se fazer uma antropologia com um setor tão demarcado pelas "ciências irmãs".

\section{Defesa do consumidor}

As primeiras associações voltadas à defesa do consumidor começaram a surgir no Brasil na década de 1970, quase sempre inspiradas em similares de outros países. O debate sobre o tema, porém, só se popularizou duas décadas depois, com a promulgação do Código de Proteção e Defesa do Consumidor $^{31}$. Além de fortalecer a atuação das entidades civis, a nova legislação fez surgir um amplo leque de instituiçõoes estatais especificamente 
voltadas a intervir nas relações de consumo. A partir de então, cada vez mais o tema passou a fazer parte do dia a dia das transações no mercado, e o próprio termo "consumidor" vem sendo empregado para designar uma imensa gama de experiências e papéis sociais ${ }^{32}$.

Esse processo de incorporação de novas perspectivas e princípios nas relações entre "consumidores" e "fornecedores" despertou o interesse em pesquisar situações em que os direitos do consumidor são tematizados e reivindicados. Uma das principais vertentes desse estudo é o acompanhamento de conflitos surgidos no mercado de consumo, e os mecanismos colocados em operação para resolvê-los ${ }^{33}$. As reflexões apresentadas a seguir dizem respeito especificamente a situações em que o consumidor recorre a instituições estatais para a implementação do que acredita serem os seus direitos. Por esse motivo, foram privilegiadas as instituições que prestam atendimento a reclamações individuais, em três vertentes: no âmbito administrativo, o Procon (Coordenadoria Estadual de Proteção e Defesa do Consumidor); na esfera policial, a Delcon (Delegacia de Crimes contra a Economia e Defesa do Consumidor); e, no judiciário, o Juizado Especial Cível (antigo Juizado de Pequenas Causas) ${ }^{34}$.

Não seria possível apresentar aqui uma descrição exaustiva das características e procedimentos de cada uma dessas instituições. Cabe observar, porém, que todas elas impõem certos requisitos formais para que a reclamação possa ser registrada e, eventualmente, atendida. Em primeiro lugar, é preciso comparecer pessoalmente, embora os horários de funcionamento desses órgãos coincidam com os da jornada regular de trabalho ${ }^{35}$. Além disso, a queixa não pode ser formalizada sem que o consumidor apresente certas informações e/ou documentos. Também é preciso ter tempo, disposição e saúde para enfrentar longas filas - que, no Procon, podem significar até duas horas de espera. Finalmente, o consumidor deve ter condições de aguardar a tramitação do caso, que pode se prolongar por meses e até anos ${ }^{36}$.

Sob esse aspecto, um detalhe aparentemente banal se revela particularmente significativo: nas três instituições pesquisadas, há barreiras concretas para 
o acesso de quem as procura. Todas funcionam em edificações recuadas em relação à rua e sem identificação clara de suas finalidades e horários de atendimento. Na Delcon, em particular, a porta é mantida fechada, sendo preciso tocar a campainha para falar com a recepcionista ${ }^{37}$. Mais que uma curiosidade etnográfica, encontra-se aí um emblema material e sintético das relações dos órgãos estatais de defesa do consumidor com o público: em princípio abertos a todos os consumidores, titulares dos mesmos direitos, eles só acolhem de fato aqueles que puderem se adaptar aos seus próprios códigos e procedimentos.

Assim, além do enquadramento legal da disputa, que freqüentemente implica uma completa redefinição da queixa inicialmente formulada, as etapas processuais e normas específicas de cada instituição promovem, ao mesmo tempo, uma classificação dos próprios consumidores. A maior ou menor possibilidade de obter um resultado favorável irá depender, entre outros aspectos, de sua disponibilidade de tempo, acesso aos meios de transporte, condições de saúde, recursos econômicos e familiaridade com procedimentos legais e burocráticos. Assim, as condições concretas para o exercício de seus direitos recortam o conjunto dos consumidores em categorias de pessoas mais ou menos credenciadas para exercê-los. Justamente porque operam a partir de normas universalizantes, as instituições estatais acabam constituindo diferenças ou reforçando desigualdades produzidas em outras dimensões da vida social.

A investigação teria pouca relevância, porém, se apenas chegasse a constatar, também na esfera dos direitos do consumidor, algo que sabidamente ocorre em outras vertentes das relações com a organização estatal no Brasil: a igualdade formal se traduzindo em desigualdade de fato. É nesse ponto, justamente, que a abordagem etnográfica e a inspiração fornecida pela tradição teórica da disciplina permitem ir além, tanto na compreensão das especificidades das relações entre consumidores, fornecedores e instituições estatais, quanto indicando caminhos para a reflexão sobre outras dimensões do Estado.

Mesmo uma observação preliminar das instituições estatais de defesa do consumidor deixa entrever que não é possível considerá-las de modo 
independente e paralelo, como se fossem unidades autônomas. É claro que cada uma delas possui características particulares, a começar por sua vinculação a diferentes instâncias da organização estatal e pelas atribuições específicas que lhes são conferidas pela legislação. Ao mesmo tempo, como já foi indicado, cada uma delas estabelece critérios específicos para que a legitimidade da queixa do consumidor seja reconhecida e para que o caso tenha andamento.

No entanto, justamente porque nem todos os consumidores podem se adaptar a tais exigências, qualquer demanda tende a se desdobrar no tempo e no espaço, isto é, num trajeto em que o consumidor (e, com ele, o fornecedor) recorre a diferentes instituições em busca de seus direitos. Por essa razão, não há descontinuidades significativas na natureza das reclamações apresentadas ao Procon, à Delcon e ao Juizado Especial Cível. Trata-se, fundamentalmente, dos mesmos casos, que circulam entre os vários órgãos estatais, independentemente de suas atribuições formais específicas ${ }^{38}$.

Cumulativamente, essa dinâmica afeta a própria organização interna de cada instituição, ao influir no volume e tipo de demanda que cada uma recebe ${ }^{39}$. Suas regras e práticas só podem ser compreendidas, assim, no conjunto das relações que entretêm tanto umas com as outras quanto com os consumidores e fornecedores em cujos conflitos são chamadas a intervir. Torna-se possível, portanto, considerar as relações entre os consumidores, os fornecedores e os órgãos estatais (e deles entre si) como momentos de um mesmo sistema, que articula e dá sentido a um grande número de ações aparentemente dispersas (Lévi-Strauss, 1988). Os próprios termos "consumidor" e "fornecedor", aliás, só fazem sentido numa perspectiva relacional.

Um ponto de partida para a compreensão dos princípios organizadores dessas relações, bem como do padrão de reciprocidade que tal dinâmica configura, pode ser encontrado nos movimentos daqueles que buscam solucionar problemas decorrentes de suas transações no mercado. A etnografia revela que, na perspectiva dos consumidores, a relação com cada instituição representa apenas um fragmento, e nem sempre o mais 
significativo, de um mesmo trajeto, que se desdobra a partir de uma mesma demanda, e que é vivido como uma experiência unitária ou "total" (Mauss, 1988).

Esse deslocamento de perspectiva permite perceber nas queixas apresentadas às instituições estatais de defesa do consumidor, apesar da diversidade concreta dos casos, uma característica comum: nenhuma reivindicação se reduz a seu conteúdo material. Além do prejuízo econômico, toda reclamação envolve também questões de honra, honestidade, respeito e boa fé. Em muitos casos, nem é possível calcular o valor monetário do prejuízo reclamado pelo consumidor - que ele mesmo, aliás, considera irrisório. Sua expectativa, porém, não é apenas garantir o exercício de seus direitos econômicos, mas obter a deferência e a consideração que lhe foram negadas numa transação mal-sucedida. Enfim, trata-se de obter ou restabelecer alguma espécie de equivalência com o fornecedor, levando-o a reconhecer que faltou com a atenção e o respeito devidos a um parceiro legítimo de trocas.

Essa dimensão - que, na falta de um termo mais adequado, pode ser denominada "moral" - nãoé, de modo algum, um componente secundário das relações entre consumidores e fornecedores. Ao contrário, a etnografia indica haver certos "presssupostos morais" que viabilizam (ou não) as transações econômicas: em especial, o reconhecimento da outra parte como alguém digno de parceria. Além de possibilitar as trocas, esses pressupostos articulam também os conflitos que delas decorrem.

As relações no mercado de consumo, porém, são reconhecidamente assimétricas $^{40}$. Assim, diante de uma transação mal-sucedida, a parte mais vulnerável procura se associar a um parceiro mais poderoso: as instituições estatais de defesa do consumidor, cuja própria existência se baseia no reconhecimento dessa vulnerabilidade. Entretanto, como se viu, tudo se passa como se o consumidor se visse diante de outra espécie de fornecedor, também capaz de definir unilateralmente as regras de suas relações. E, como conseqüência dessas regras, as relações litigiosas entre consumidor e fornecedor podem produzir vínculos tão ou mais duráveis que os que unem os parceiros de trocas satisfatórias. 
No entanto, seria equivocado supor que os tortuosos trajetos percorridos pelos consumidores em busca de seus direitos sejam orientados exclusivamente pelos dispositivos legais e pelas normas das instituições. A explicação permaneceria insuficiente se negligenciasse as próprias razões que dão origem às disputas. Sob esse aspecto, cabe notar que o defeito num produto, ou até mesmo o atraso na entrega de um bem ou serviço, não conduzem imediatamente à animosidade. Os consumidores tendem a considerá-los como contratempos mais ou menos rotineiros, embora sempre desagradáveis. O que desencadeia o conflito - e faz com que ele se traduza no vocabulário formal dos direitos - não é o dano sofrido, mas a recusa do fornecedor em reconhecê-lo e repará-lo, isto é, o rompimento dos compromissos implícitos de respeito e boa-fé que haviam possibilitado a efetivação do negócio.

Desse modo, ao invés de comandar a forma e o conteúdo das disputas, os dispositivos legais e as normas das instituições é que são englobados por princípios mais gerais, que estão na base das relações entre consumidores e fornecedores ${ }^{41}$. O interesse econômico não é capaz de explicar, por exemplo, os inúmeros casos em que o consumidor se dispõe a enfrentar um longo processo burocrático ou presta queixa numa delegacia apenas para obter um pedido formal de desculpas. A lógica impessoal e pragmática do mercado capitalista, porém, não é capaz de subsumir o princípio muito mais geral da reciprocidade (Mauss, 1988) (2. $^{4}$

E assim como entre consumidor e fornecedor há algo mais que simples prestações econômicas, também a relação entre o consumidor e o órgão estatal transcende o formalismo jurídico. Se considerássemos apenas o índice de sucesso de seus procedimentos, a expressiva credibilidade de que desfrutam as instituições estatais de defesa do consumidor permaneceria um resíduo inexplicado e contraditório ${ }^{43}$. Mesmo em casos não resolvidos, porém, não é raro ver o consumidor agradecer, com sincera veemência, o empenho demonstrado pelos funcionários na tentativa de resolver o problema apresentado. O que essas manifestações parecem indicar é que, apesar da ineficácia de suas providências, a instituição se mostrou capaz de oferecer 
exatamente aquilo que havia faltado na relação com o fornecedor, desencadeando o conflito: o reconhecimento do consumidor como um parceiro legítimo, digno de respeito e atenção.

Em relação às reflexões mais gerais deste artigo, é possível desenvolver a partir daí duas ordens de considerações. Em primeiro lugar, torna-se necessário relativizar algumas interpretações correntes, em especial a "impessoalidade" e a "fugacidade" das relações no mercado de consumo contemporâneo. Da mesma forma, torna-se possível ampliar o escopo das análises desenvolvidas por outras disciplinas, que tendem a ver na questão dos direitos do consumidor apenas a redução do cidadão às injunções do mercado, com a concomitante redução dos direitos políticos da esfera pública a direitos econômicos, de ordem privada. A abordagem etnográfica indica, ao contrário, que o interesse "econômico" jamais se reduz ao material e ao individual, e que a oposição público/privado pode ser englobada num sistema mais amplo de relações de troca.

A segunda ordem de considerações diz respeito a reflexões clássicas no próprio campo da antropologia. A coexistência, na vida contemporânea, de duas modalidades de troca - a lógica do dom e a lógica do mercado já foi observada por diversos autores: além de Mauss (1988) e Lévi-Strauss (1982), é possível lembrar, por exemplo, a importante contribuição de Polanyi (1980). A etnografia das disputas relativas a direitos do consumidor sugere, porém, que em certos contextos essas lógicas aparentemente distintas podem ser indissociáveis, e que é exatamente isto o que ocorre num território de algum modo totalmente alheio aos princípios da troca maussiana: a reivindicação formal dos direitos do consumidor.

\section{Análise antropológica de setores do Estado: algumas sugestões}

Não é nosso propósito, neste artigo, chegar a qualquer conclusão definitiva sobre as instituições que estamos estudando. Ao contrário, a intenção é esboçar uma perspectiva de análise de setores do Estado que, fundada 
numa tradição teórica construída a partir de outros contextos de pesquisa, venha a contribuir para engrossar o coro dos que defendem a dissolução dos "divisores" tão prejudiciais a nossa disciplina. Entretanto, alguns apontamentos podem ser realizados a partir de uma comparação preliminar das duas vertentes da organização estatal abordadas acima.

Evidentemente, de um ponto de vista sociológico, tanto o exército quanto as instituições de defesa do consumidor compartilham um mesmo fundo sócio-histórico, apresentam traços comuns que remetem às especificidades da formação de nosso Estado ou, ainda, estão amparados por um mesmo ethos social que recobre a vida "brasileira". No entanto, que indícios teríamos ao compará-los sob a perspectiva de um olhar mais distanciado, isto é, para além de suas formas institucionais e de suas funções no aparelho estatal?

Nos dois casos, vimos que as maneiras pelas quais estas instituições operam extrapolam o arcabouço legal/formal: os órgãos de defesa do consumidor não se limitam a regular as relações de mercado e a promover o consenso individual, mas atuam também na construção de pessoas morais, operando portanto na lógica da troca-dom; o exército, da mesma forma, não é tão-somente uma instituição pública voltada para a defesa, mas uma corporação cuja dinâmica impõe fronteiras simbólicas em relação à sociedade e institui uma hierarquia em relação a ela.

Desse modo, é possível identificar nas duas vertentes da organização estatal analisadas operações que envolvem categorias mais gerais e mais abstratas que aquelas que se ancoram no devir histórico: se, no que diz respeito aos órgãos de defesa do consumidor, partimos de uma assimetria dada na esfera privada para chegar a uma simetria a partir da intervenção hierarquizada do público, no que se refere ao exército, partimos de uma simetria dada pela constituição de um órgão público para chegar a uma assimetria em relação à sociedade, dada pela constituição de uma esfera privada (ou "privatizada") a partir da hierarquia.

Este duplo movimento poderia ser explicado por uma série de razões. Neste contexto, gostaríamos apenas de enfatizar uma, que nos parece a 
mais importante, e que está na base de qualquer arranjo institucional: a constituição dos mecanismos de troca, seja ela entre indivíduos cuja transação inicial foi mal-sucedida (e, assim, passam a estar ligados pelos vínculos da "guerra"), seja ela entre indivíduos que só trocam entre si por se encontrarem em permanente estado de guerra. As experiências sociais que estão na base dessas instituições remetem, assim, ao plano mais amplo da constituição de "pessoas morais" no interior da nossa sociedade. Por isso, seja no plano da "guerra", seja no plano da "troca" (que, como ensina Lévi-Strauss, podem ser concebidas como a atualização de um mesmo princípio geral), lidamos com experiências "totais" que só fazem sentido no plano da construção da pessoa, englobando o formalismo jurídico-legal que remete ao estreito plano das funções institucionais destes setores do Estado.

Desse modo - e, aqui, o intuito é salientar o que há de promissor no estudo do Estado a partir de uma perspectiva antropológica-, os cálculos de engenharia institucional freqüentemente realizados para entender a relação Estado-sociedade (que sempre aparece mediada pela categoria "indivíduo") não se mostram suficientes para entender a dinâmica estrutural que está por trás do sentido que as pessoas dão às suas instituições.

Claro que este artigo também não resolve o problema. É interessante, contudo, observar que pesquisas etnográficas recentes têm revelado como nossas instituições "hierarquizam", "individualizam" ou "pessoalizam" relações que, formalmente (ou ao menos em princípio), "deveriam" ocorrer de outra forma. Assim, a lógica do mercado é tão insuficiente para se entender as estratégias dos consumidores quanto o é a lógica institucional para se entender o exército. Cabe ressaltar, finalmente, que o olhar antropológico tem muito ainda a oferecer à análise de nossas instituições centrais. Não basta vê-las sob o ângulo das agências que reprimem nossos "objetos tradicionais": mesmo este ângulo, acreditamos, está englobado por categorias mais profundas de sua constituição. 
Bevilaqua \& Leirner. Notas sobre a Análise Antropológica

\section{Notas}

1 Uma primeira versão deste artigo foi lida e comentada por Edilene Coffaci de Lima e José Guilherme C. Magnani, a quem gostaríamos de expressar nossos agradecimentos. Agradecemos também aos pareceristas anônimos da Revista de Antropologia, por seus comentários e sugestões.

2 De certa maneira, é possível considerar os estudos de processos eleitorais como o marco inicial dessa tendência, com trabalhos como os de Sá (1974) e Caldeira (1980). Já nos anos 80, ainda que de maneira mais sistemática somente nos anos 90, os antropólogos começam a explorar etnograficamente o Estado, através de temas - para citar alguns - como congresso nacional ou congressistas (Costa, 1981; Teixeira, 1999; Abreu, 2000; Kuschnir, 1998), exército (Castro, 1990; Leirner, 1997) e imposto de renda (Bevilaqua, 1995). Isto, sem considerar uma linha já mais tradicional de pesquisa sobre as agências de contato e gerenciamento estatal das populações indígenas (Lima, 1995).

3 Pensamos em autores que, sob inspiração de Mauss e Lévi-Strauss (ainda que abrindo uma perspectiva diversa), procuraram pensar o "político" em relação às modalidades de troca e reciprocidade. Além de Clastres e sua conhecida fórmula de "sociedade contra o Estado", incluem-se nesse grupo M. Gauchet (1977) e A. Adler (1977), que talvez sejam, inclusive, dois dos melhores comentadores de Clastres. Não nos referimos, portanto, a autores franceses de inspiração mais próxima ao marxismo, como Godelier ou mesmo Balandier.

4 No Brasil, as primeiras reflexões sobre o "familiar" e o "distante" na investigação antropológica aparecem no conhecido debate entre DaMatta (1974) e Velho (1978). Mais recentemente, os problemas e perspectivas da antropologia das chamadas "sociedades complexas", em relação à tradição disciplinar de investigação em sociedades de pequena escala, são discutidos, por exemplo, por Montero (1991), Magnani (1996), Goldman (1995) e Goldman \&Lima(1999).

5 Utilizamos aqui a expressão de J. Goody, no sentido que lhe dão Goldman \& Lima (1999) ao se manifestarem contra a existência de "dois tipos de Antropologia", como decorrência de "dois tipos de objeto". 
Revista de Antropologia, São Paulo, USP, 2000, v. 43 nº 2.

6 Empregamos a expressão "setores do Estado" para enfatizar que o Estado não é uma instituição monolítica. Ao contrário, comporta diferentes dimensões e agências que não são homogêneas e, muitas vezes, chegam a constituir grupos com contornos bastante particulares. Os exemplos etnográficos apresentados mais adiante deverão contribuir para esclarecer melhor esta noção.

7 Como é sabido, existe no Brasil uma longa tradição de estudos da sociedade nacional, inclusive em contextos urbanos, que remonta ao início do período republicano. Referimo-nos aqui mais especificamente às contribuições das últimas três décadas, quando a antropologia adquire maior visibilidade e reconhecimento no país, por conta da conjugação de fatores políticos, acadêmicos e institucionais (cf. Durham, 1988; Magnani, 1996).

8 Não é nossa intenção neste texto fazer um balanço destas contribuições. Cabe lembrar, porém, que uma das primeiras versões desse debate se desenvolveu em torno dos conceitos de "cultura" e "ideologia" (Durham, 1982; Velho \& Viveiros de Castro, 1975). Neste caso, fica claro que o entorno da discussão é uma sociologia de inspiração marxista, que apontava insuficiências de conceitos como o de "cultura", particularmente o que era visto como sua tendência a ocultar as contradições mais fundamentais de nossa sociedade. Para uma versão contemporânea dessa reflexão, ver Goldman \& Lima (1999). Para um balanço das contribuições desenvolvidas em outras tradições da disciplina sobre a antropologia das "sociedades complexas", ver Goldman (1995).

9 Entre outros trabalhos, cabe mencionar as teses de Montes (1983) e Magnani (1984), que identificam nas práticas de lazer e na religiosidade popular a construção de discursos e formas de sociabilidade não contempladas pela conjugação sociológica clássica "Estado - Classes Sociais - Trabalho". Nessas análises, o conceito de ideologia ganha uma nova dimensão. Também é interessante se pensar em teses como a de Duarte(1983), mostrando a construção de uma concepção popular de doença que passa longe da medicina oficial. Aqui, a idéia dumontiana de valor e classificação se sobrepõe à concepção marxista de ideologia.

10 Como observou Durham: "A antropologia sempre demonstrou especial interesse pelas minorias despossuídas e dominadas de todos os tipos (índios, negros, camponeses, favelados, desviantes e 'pobres' em geral) 
Bevilaqua \& Leirner. Notas sobre a AnÁlise Antropológica

em detrimento do estudo dos grupos ou classes politicamente dominantes e atuantes. Quanto aos temas, sempre revelou uma afinidade particular por aqueles que eram claramente periféricos à grande arena das lutas políticas: dedicou-se muito mais ao estudo da família, da religião, do folclore, da medicina popular, das festas do que à análise do Estado, dos partidos políticos, dos movimentos sindicais, das relações de classe, do desenvolvimento econômico" (1988: 18). Desse modo corre-se o risco de admitir, por contraste, que os antropólogos, enquanto os outros desses outros, seriam os agentes das elites, do Estado, das burocracias etc., uma proposição que nos parece inaceitável.

11 Esta declaração, feita pelo cientista político Fábio Wanderley Reis durante uma reunião da Associação Nacional de Pós-Graduação em Ciências Sociais, faz parte de um longo debate narrado e analisado por Mariza Peirano (1996).

12 A expressão é empregada por Magnani (1996).

13 Como observou recentemente Manuela Carneiro da Cunha, "um grande equívoco é só estudar grupos minoritários. Em todas as teses sobre partidos políticos na USP, 90\% são sobre o PT e ninguém estuda o PFL, que é interessantíssimo e importantíssimo de ser estudado. Estudar o PFL não quer dizer estar dissociado de uma agenda política" (1998: 86).

14 Além da vigorosa linhagem de africanistas que inaugura esse campo de estudos, cabe mencionar as críticas que, na década de 1960, levaram à valorização não mais das instituições, mas do processo político enquanto tal e/ou dos valores e representações. Perspectivas mais recentes contribuem para a relativização da própria concepção universalizante do poder. Para um balanço crítico dessa trajetória, ver Palmeira \& Goldman (1996: 1-12).

15 Uma importante exceção é o Núcleo de Antropologia da Política (Nuap), de onde têm se originado algumas das mais importantes contribuições recentes. O Nuap reúne investigadores de diferentes instituições, que desenvolvem pesquisas etnográficas sobre a esfera da política.

16 Nesse sentido, vale lembrar uma entrevista recente com o antropólogo Eduardo Viveiros de Castro: "Boa parte do que se fez em antropologia das 
Revista de Antropologia, São Paulo, USP, 2000, v. 43 nº 2.

sociedades complexas limitava-se a projetar para o contexto urbano os conceitos e o tipo de objeto característico da antropologia clássica. Isso não foi muito longe, pois para fazer uma verdadeira projeção, teria que ser uma projeção no sentido geométrico da palavra: o que se deve preservar são as relações, não os termos" (1999: 126).

17 Esta formulação é do antropólogo Marcos Lanna, em comunicação pessoal. Com ele também compartilhamos algumas das idéias que acabamos de expor, em especial a importância de se desenvolver uma antropologia "do centro" - isto é, do Estado - nas sociedades de tradição ocidental.

18 Nesse ponto, a organização burocrática vem a reboque de processos sociais mais amplos, como a constituição de uma elite dirigente, como mostram, por exemplo, análises que partem de conceitos como patrimonialismo e patriarcalismo (Faoro, 1989; Schwartzman, 1982).

19 Um balanço desses estudos está em Guimarães (1999: 17-20).

20 Marcel Mauss já apontava nessa direção, no Ensaio sobre a Dádiva (1988). A legitimidade dessa abordagem também não deixou de ser reconhecida por expoentes da vertente britânica da disciplina. Meyer Fortes, por exemplo, observa: "Pode haver um paralelo estrutural mais estreito entre o sistema de sindicatos de um país europeu e o sistema de linhagens de um estado africano como o Ashanti, que entre este último e as assim chamadas 'redes de parentesco', tão valorizadas em alguns textos recentes" (apud Eisenstadt, 1961: 212; tradução livre).

21 Há um projeto do exército, que vem sendo desenvolvido desde 1995, para se chegar ao ano 2000 com um índice de $80 \%$ de militares de carreira.

22 O corpo de reserva é formado por [a] "militares da reserva remunerada", ou seja, militares de carreira aposentados, e [b] os "demais cidadãos em condições de convocação ou de mobilização para a ativa" (Estatuto dos Militares, Art. $\left.4^{\circ}, \S 1^{\circ}\right)$. Note-se que os chamados conscritos, recrutas do serviço obrigatório, quando passam para a reserva não entram para a categoria da reserva remunerada, sendo colocados na condição de $[b]$ : "demais cidadãos...". 
Bevilaqua \& Leirner. Notas sobre a Análise Antropológica

23 Vale ressaltar que este direito é dado somente aos que estão nesta carreira, não incluindo, portanto, os soldados recrutados anualmente pelo serviço militar obrigatório.

24 Resumindo, a dificuldade consistiu em liberar acesso à pesquisa num pelotão de fronteira na área do Projeto Calha Norte. No entanto, tinha acesso "liberado" a locais como a Escola de Comando e Estado-Maior do exército ou o Quartel General em Brasília.

25 Pessoas que estavam ligadas a estes locais referidos acima: quase uma absoluta totalidade de coronéis e generais se "encarregavam" do contato com o pesquisador e a instituição a que ele pertence, o que era feito, obviamente, à maneira militar.

26 "Melhor situado" não representa necessariamente estar acima na cadeia de comando, mas sim estar com uma possibilidade estrutural de em algum momento se situar no topo dela, enquanto "pior situado" representa estar numa posição em que provavelmente o indivíduo não chegará ao topo da cadeia de comando (especificamente ao generalato), ainda que ele possa se situar, num dado momento, "acima" do primeiro. Os detalhes deste arranjo estão descritos em Leirner (1997).

27 "Uma característica de qualquer grupo político é, conseqüentemente, sua invariável tendência para divisões e oposição de seus segmentos, e outra característica é a sua tendência para a fusão com outros grupos de sua própria ordem em oposição a segmentos políticos maiores do que o próprio grupo. Os valores políticos, portanto, estão sempre em conflito, falando-se em termos de estrutura. Um valor vincula uma pessoa a seu grupo e um outro a um segmento do grupo em oposição a outros segmentos do mesmo, e o valor que controla suas ações é uma função da situação social em que a pessoa se encontra. Pois uma pessoa vê a si mesma como membro de um grupo apenas em oposição a outros grupos, e vê um membro de outro grupo como membro de uma unidade social, por mais que esta esteja fragmentada em segmentos opostos" (Evans-Pritchard, 1978: 149).

28 Dentre as características mais importantes do tipo burocrático, Weber (1966: 20-21) destaca a hierarquia de cargos, esferas de competência diferenciadas, qualificação em bases técnicas e sujeição à disciplina. 
Revista de Antropologia, São Paulo, USP, 2000, v. 43 nº 2.

29 A cada ano, as pessoas saem classificadas numa lista que abrange todos os membros que pertencem à carreira, de cabos a generais.

30 Talvez a imagem da "fila indiana" seja mais clara para exemplificá-la.

31 Lei no 8.078, de 11/09/90. O Código entrou em vigor em março de 1991.

32 Pacientes em consultórios e hospitais, estudantes, leitores, usuários de serviços públicos, torcedores de times de futebol e até fiéis de igrejas são hoje considerados "consumidores".

33 A pesquisa, ainda em andamento, está sendo realizada em Curitiba-PR. A capital paranaense esteve presente nos primeiros passos do debate sobre os direitos do consumidor no Brasil. Foi sede, por exemplo, do $1^{\circ}$ Congresso Nacional de Defesa do Consumidor, em 1976. No mesmo ano, surgiu na cidade uma das primeiras entidades civis de defesa do consumidor do país, a Associação de Defesa e Orientação do Cidadão (Adoc). Por outro lado, cabe mencionar que Curitiba foi e continua sendo "mercado-teste" de diversos produtos, uma escolha certamente motivada pelo perfil demográfico e sócioeconômico da cidade. Entretanto, ao longo do tempo, disseminouse a opinião - compartilhada e reivindicada pelos moradores - de que os curitibanos seriam "mais exigentes" no que diz respeito à qualidade dos produtos e aos seus direitos de consumidores.

34 Embora não esteja voltado especificamente a casos dessa natureza, o Juizado Especial Cível, ao qual competem as ações consideradas de menor complexidade e que envolvam até quarenta salários mínimos, é a instância do Poder Judiciário para a qual converge a maior parte dos litígios envolvendo direitos do consumidor.

35 Durante a pesquisa, foi possível constatar com certa freqüência casos em que o consumidor acabou perdendo o emprego por ser obrigado a faltar constantemente para acompanhar a tramitação de sua queixa nas instituições de defesa do consumidor.

36 As condições de atendimento variam, evidentemente, conforme a instituição, assim como as exigências para o registro dos casos e o tempo de tramitação dos processos. 
Bevilaqua \& Leirner. Notas sobre a Análise Antropológica

37 Esta característica diz respeito à sede da Delcon onde se concentraram as observações, no primeiro semestre de 1999. Algum tempo depois, a delegacia passou a ocupar novo endereço - a quarta mudança em menos de cinco anos.

38 Durante a pesquisa de campo, foi possível reencontrar seguidamente na Delcon, por exemplo, casos que haviam sido observados inicialmente no Procon. Da mesma forma, é possível acompanhar no Juizado Especial o desdobramento de conflitos que haviam sido levados inicialmente tanto ao Procon quanto à Delcon.

39 Em certo período, o Procon suspendeu a realização de cálculos de juros de financiamentos. Em pouco tempo, foi necessário voltar atrás, tamanha era a demanda encaminhada pelos demais órgãos, que não oferecem esse serviço. Da mesma forma, a grande maioria das queixas apresentadas à Delcon onde as exigências para o registro de ocorrências são menores - não diz respeito a crimes. Por esse motivo, a delegacia se viu obrigada a realizar audiências de conciliação, que não fazem parte de suas atribuições mais fundamentais.

40 Embora as preferências dos consumidores orientem a oferta de bens e serviços, cada um deles, individualmente, está desprovido de meios para avaliar as condições de qualidade e segurança dos produtos que adquire, ou para alterar os termos da imensa maioria dos contratos. Como observa a jurista Claudia Lima Marques, "as relações contratuais se despersonalizaram, aparecendo os métodos de contratação estandardizados, como os contratos de adesão e as condições gerais dos contratos. Hoje estes métodos predominam em quase todas as relações entre empresas e consumidores, deixando claro o desnível entre os contratantes - um, autor efetivo das cláusulas, e outro, simples aderente" (1998: 33).

41 Não se quer afirmar, com isso, que os conflitos envolvendo direitos do consumidor tenham somente um conteúdo "moral", mas que esta é uma dimensão constitutiva deles. A indissociabilidade moral/legal em casos dessa natureza, aliás, foi também observada em disputas em tribunais de pequenas causas nos Estados Unidos (Cardoso de Oliveira, 1996 e 1996a), indicando se tratar de um fenômeno muito mais geral, ainda que possa assumir características particulares em diferentes contextos. 
Revista de Antropologia, São Paulo, USP, 2000, v. $43 n^{\circ} 2$.

42 Adotando uma perspectiva bastante próxima da de Mauss, o historiador Fernand Braudel argumenta que o capitalismo não reunifica toda a economia sob um único código (1987). Na antropologia contemporânea, são bem conhecidas as reflexões de Sahlins (1979) sobre os fundamentos simbólicos da organização da economia capitalista.

43 De um total de 2.260 audiências realizadas pelo Procon-PR em 1998, por exemplo, apenas 500 reclamações foram resolvidas. Dentre as demais, 18 foram consideradas improcedentes, 742 foram encerradas por outras razões e 1.000 não foram resolvidas.

\section{Bibliografia}

ABREU,L.E.L.

2000 Os labirintos do minotauro. Política, troca e linguagem, tese de doutorado, Brasília, Depto de Antropologia, Universidade de Brasília.

ADLER, A.

1977 "Fazedores de chuva, fazedores de ordem", in CLASTRES, P. et al. (org.), Guerra, Religião e Poder, Lisboa, Edições 70.

BENDIX, R.

1996 Construção nacional e cidadania, São Paulo, Edusp.

BEVILAQUA, C.

1995 Se esconder o leão pega, se mostrar o leão come: um estudo antropológico do imposto de renda, Paraná, dissertação de mestrado, Universidade Federal do Paraná.

BRAUDEL, F.

A dinâmica do capitalismo, Rio de Janeiro, Rocco.

- 133 - 
Bevilaqua \& Leirner. Notas sobre a Análise Antropológica

\section{CALDEIRA, T. R.}

1980 "Para que serve o voto? As eleições e o cotidiano na periferia de São Paulo, in LAMOUNIER, B. (org.), Voto de desconfiança-eleições e mudança política no Brasil, 1970-1979, Petrópolis, Vozes.

\section{CARDOSODE OLIVEIRA, L.R.}

1996a "Entre o justo e o solidário: os dilemas dos direitos de cidadania no Brasil e nos Estados Unidos", Revista Brasileira de Ciências Sociais, $\mathrm{n}^{\circ} 31$, São Paulo, ANPOCS.

1996b "Justiça, solidariedade e reciprocidade: Habermas e a Antropologia", in OLIVEIRA, R. C. \& OLIVEIRA, L. R. C. (org.), Ensaios antropológicos sobre moral e ética, Rio de Janeiro, Tempo Brasileiro.

\section{CARNEIRO DA CUNHA, M.}

1998 "Saberes locais, tramas identitárias e o sistema mundial na antropologia de Manuela Carneiro da Cunha”, entrevista realizada por Carlos Machado Dias Jr, Renato Sztutman, Stélio Marras e Valéria Macedo. Sexta-Feira. Antropologia, Artes e Humanidades, São Paulo, vol. 3: 80-92, Pletora.

\section{CASTRO, C.}

1990 O espírito militar: um estudo de antropologia social na Academia Militar das Agulhas Negras, Rio de Janeiro, Zahar.

\section{CLASTRES, P.}

1978 A sociedade contra o Estado, Rio de Janeiro, Francisco Alves.

\section{COSTA, M. C.S.}

1981 Os caminhos da Casa: um estudo antropológico do Congresso Nacional, Rio de Janeiro, dissertação de mestrado, Museu Nacional. 
Revista de Antropologia, São Paulo, USP, 2000, v. 43 nº 2.

COSTA, V.R.

1985 “Com rancor e com afeto: rebeliões militares na década de 30", Ciências Sociais Hoje, Rio de Janeiro, ANPOCS.

DA MATTA, R.

1974 "O ofício do etnólogo, ou como ter 'anthropological blues", Cadernos do PPGAS, Rio de Janeiro, Museu Nacional.

DUARTE, L.F.D.

1983 Da vida nervosa das classes trabalhadoras, Rio de Janeiro, Jorge Zahar.

DUMONT,L.

1992 Homo hierarchicus - o sistema de castas e suas implicações, São Paulo, Edusp.

1993 Ensaios sobre o individualismo, Lisboa, Dom Quixote.

DURHAM,E. R.

1982 "Cultura e ideologia", Dados, Rio de Janeiro, vol. 27 (1): 71-89. Rio de Janeiro, 1984.

1988 "A pesquisa antropológica com populações urbanas: problemas e perspectivas", in CARDOSO, R. (org.), A aventura antropológica, Rio de Janeiro, Paz e Terra.

EISENSTADT, S.N.

1961 "Anthropological studies of complex societies", Current Anthropology, vol. 2(3): 201-22.

EVANS-PRITCHARD, E. E.

1978 Os Nuer, São Paulo, Perspectiva.

$-135-$ 
Bevilaqua \& Leirner. Notas sobre a Análise Antropológica

EVANS-PRITCHARD, E. E. \& FORTES, M. (Ed)

1940 African political systems London, Oxford University Press.

FAORO, R.

1989 Os donos do poder, 2 v. 8.ed., Rio de Janeiro, Globo.

\section{GAUCHET, M.}

1977 "A dívida do sentido e as raízes do Estado", in CLASTRES, P. et al., Guerra religão e poder, Lisboa, Edições 70.

\section{GOLDMAN, M.}

1995 "Antropologia contemporânea, sociedades complexas e outras questões", Anuário Antropológico/93, Rio de Janeiro, Tempo Brasileiro.

GOLDMAN, M. \& LIMA, T.

1999 "Como se faz um grande divisor?", in GOLDMAN, M.(org.), Alguma Antropologia, Rio de Janeiro, Relume-Dumará.

\section{GUIMARÃES, A. S.}

1999 "Classes sociais", in MICELI, S. (org.), O que ler na ciência social brasileira: Sociologia, São Paulo, Sumaré.

\section{KUSCHNIR, K.}

Política e sociabilidade: um estudo de antropologia social, Rio de Janeiro, tese de doutorado, Museu Nacional, Universidade Federal do Rio de Janeiro. 
Revista de Antropologia, São Paulo, USP, 2000, v. $43 n^{\circ} 2$.

\section{LEIRNER,P.C.}

1997

Meia-volta, volver: um estudo antropológico sobre a hierarquia militar, Rio de Janeiro, FGV/Fapesp.

\section{LÉVI-STRAUSS, C.}

1982 As estruturas elementares do parentesco, Petrópolis, Vozes.

1988 “Introdução à obra de Marcel Mauss", in MAUSS, M., Ensaio sobre a dádiva, Lisboa, Edições 70.

LIMA, A. C. S

1995 Um grande cerco de paz, Petrópolis, Vozes.

MAGNANI, J. G. C.

1984 Festa no pedaço: cultura popular e lazer na cidade, São Paulo, Brasiliense.

1996 "Quando o campo é a cidade: fazendo antropologia na metrópole", in MAGNANI, J.G. \& TORRES, L. L. (orgs.), Na metrópole - textos de antropologia urbana, São Paulo, Edusp.

\section{MARQUES, C.L.}

1998 Contratos no código de defesa do consumidor, 3 ed., São Paulo, Revista dos Tribunais.

MAUSS, M.

1988

Ensaio sobre a dádiva, Lisboa, Edições 70.

\section{MONTERO,P.}

1991 "Reflexões sobre uma antropologia das sociedades complexas", Revista de Antropologia, vol. 34, São Paulo. 
Bevilaqua \& Leirner. Notas sobre a Análise Antropológica

MONTES, M. L.

1983 Lazer e ideologia, São Paulo, tese de doutorado, Departamento de Ciências Sociais, Universidade de São Paulo.

\section{PALMEIRA, M. \& GOLDMAN, M.}

1996 Antropologia, voto e representação política, Rio de Janeiro, Contra Capa Livraria.

PEIRANO, M.

1996 A favor da etnografia, Rio de Janeiro, Relume-Dumará.

POLANYI, K.

1980 A grande transformação, Rio de Janeiro, Campus.

SÁ, M. A. F.

1974 Dos velhos aos novos coronéis: um estudo das redefinições do coronelismo, Recife, UFPE/PIMES.

SAHLINS, $\mathrm{M}$.

1979 Cultura e razão prática, Rio de Janeiro, Zahar.

\section{SCHWARTZMAN, S.}

1982

Bases do autoritarismo brasileiro, Rio de Janeiro, Campus.

TEIXEIRA, C.C.

1999 A honra da política: decoro parlamentar e cassação de mandato no congresso nacional (1949-1994), Rio de Janeiro, Relume-Dumará. 
Revista de Antropologia, São Paulo, USP, 2000, v. 43 nº 2.

\section{VELHO, G. \& VIVEIROS DECASTRO, E.}

1975 "O conceito de cultura e o estudo de sociedades complexas", Artefato, Rio de Janeiro, vol. I(1), Conselho Estadual de Cultura.

\section{VELHO,G.}

1978 "Observando o familiar", in Nunes, E. (org.), O cotidiano da pesquisa em Ciências Sociais, Rio de Janeiro, Zahar.

\section{VIVEIROS DECASTRO,E.}

1999 "Entrevista com o antropólogo E. Viveiros de Castro", por Renato Sztutman, Silvana Nascimento e Stélio Marras, Sexta-Feira. Antropologia, Artes e Humanidades, n. 4, São Paulo, Pletora.

\section{WEBER, M.}

1966 "Os fundamentos da organização burocrática: uma construção do tipo ideal", in CAMPOS, E. (org), Sociologia da burocracia, Rio de Janeiro, Zahar.

1994 Economia e sociedade, Brasília, Ed. da UnB. 
Bevilaqua \& Leirner. Notas sobre a Análise Antropológica

ABSTRACT: This article discusses some aspects of the anthropological study of the brazilian state. The argumentation is based on the statements of two very different ethnographic experiences: while the subject of the first one is the army, the second one deals with consumer defense agencies. On this aim, the article develops a preliminary reflection about theoretical and methodological problems related to this kind of investigation in our own society.

KEY-WORDS: State, Urban Anthropology, Ethnography.

Recebido em maio de 2000 